\title{
Smart Cities in India: Branded or Brain-dead?
}

\author{
Vaishali AGGARWAL, Bauhaus-Universität Weimar; Germany
}

\begin{abstract}
The notion of 'smart cities' is increasingly visible in discourses on the future of cities but Change is coming to transportation, whether we are ready for it or not. But how sustainable and digital innovation can unlock better people health and well-being, enhance safety and security and provide seamless mobility experiences. It can be argued that smartening the mobility infrastructure enables the citizens to make informed decisions, and this is indeed true- if done well, but it has a big "if."

This research engages with the key drivers of change and provides affirmative aspirations for mobility in the not-so-distant future in order to facilitate conversations about change. However, the development of possibilities (scenarios) for the government policies and business innovation is dependent on the advanced technology and socio-economic values, which are embedded in the context and culture. The research paper aims to visualize through foresight by design, plausible alternatives of sustainable future for passenger transport in Delhi to stimulate sustainable innovation developments for transportation and analyse the present innovative influences for smart mobility in Delhi to accelerate the adoption.

The first part of the paper analyses how do urban planners use the discourse of smart cities and how it has defined in India then later suggest future scenario for the future which will empower users, changing mobility models and transforming eco-system where intelligent connectivity would unite varied rage of emerging technologies to enable smarter, healthier and more resilient and economically vibrant urban life. This research considers smart mobility by outlining current challenges, suggesting technological, infrastructural and policy solutions and distilling explorations of the future into a series of 'user journeys.' It seeks to answer if 'branding of technology' can be used as a tool to create a new identity for mobility of Delhi or 'upgrade' the existing situation. How can the context of Delhi be decoded to describe the perceptions of the people?
\end{abstract}

\section{Keywords}

Livability, Sustainable Transport, Narrative transportation, Personas, inclusive design, integrated transportation system, user journey \& experience

\section{Introduction}

Future is fiction, but the cities of the future will be 'smart.' 'Smart cities' is the most fashionable concept in urban policy nowadays but the meaning of the term is often obscure in a different context. But is "smart city" just another buzzword or does it have some meaning? Smart City is considered like a winning urban strategy using information and communication technologies, business models, and solutions to increase the operational efficiency, share information with the public and improve both the quality of services and citizens welfare. 
Mobility shapes the cities, but cities are not static, they change and adapt like living organisms over time. Though historically, mobility was primarily viewed as a 'product' that includes vehicles, physical infrastructure, fuels required to move around but now mobility is approached as a 'service' for seamless movements from place to place. Therefore, strategies for measurable economic and environmental sustainability and improved traveller experience would be achieved by reducing the use of fuel and power consumption for vehicles, reduction in congestion and traveller frustration and promoting the efficient, costeffective system to eliminate adverse impacts on health and environment and would provide improved accessibility and affordability of transport providers and travellers.

However, if "smart cities" is the answer, then what was the question? How can technology and intelligent design be used for creating a better world for people? Therefore technology will be used in a manner which is no longer isolated in different devices or services; rather it would be used to surround us, support us and promise us for a better urban experience. Will everyone get the benefit from the technological transportation advances or will it be accessible only to those who have the resources or knowledge to use them? Therefore, 'how' is the crucial key for smart city/mobility solutions. However, in a rush for the smart cities, we are seeking for wrong questions.

"Smart cities" has become a buzzword in India since Prime Minister Narendra Modi outlined his vision. But the smart cities ambition remains elusive in the Indian context as cities in India face a range of challenges to meet demand and supply gaps in urban regions in areas such as water, waste management, energy, mobility, the built environment, education, healthcare and safety and if timely and adequate action is not taken, these challenges may worsen and could derail India's growth (world economic forum, 2016). Ironically, this is precisely why India desperately needs a system of smart(er) cities. Delhi, which is a second most populous city in the world (world population review, 2019) has a car-centric landscape with trends of rapid urbanization, rapidly growing economies and high level of transport related problems such as pollution, accidents, and congestions, which has an adverse impact of urban quality of life.

Can technology allow us to rectify the mistakes of the past? What new possibilities will exist with the creative use of technologies? What is the 'value' which smart mobility will provide to Delhi? To accomplish the inclusivity in mobility, we need to ask if this is the role we want mobility to play then how do we ensure things are in place for this to happen? Smart mobility for whom? Cities for whom? The question is not how do we make my city smarter by smart mobility? or even 'how do I make it more efficient?' Rather we should ask, 'how can smart mobility be implemented in the places like Delhi where planning is both essential and broken? How can the gap between the bottom up and top-down initiatives be reduced? Does smart mobility provides solutions for the transportation problems in Delhi or does it raise the questions of resistance of being 'alternative smart' with a power of 'image'?

\section{Smart Cities}

\subsection{Definition}

Despite the ongoing discussions over the past few years, there is no agreed definition of a 'smart city.' The label "smart city" is a fuzzy concept and is used in ways that are not always consistent. There is neither a single template of framing a smart city, nor a one-size-fits-all 
definition of it (O'Grady and O'Hare, 2012). There is still confusion about what a smart city is, especially since several similar terms are often used interchangeably. Collective smartness is an important aspect of smart cities because it supports creative human capital, learning, technological development, and citizen participation. The definition of 'smart city' is not just based on the use of 'ICT.' According to Hollands (2008), the smart city is based on "urban labeling" phenomenon that downplays some of the adverse effects networked infrastructures on cities. Cities by nature are supposed to be smart, creative and cultural, and by using this marketing label a disjuncture between reality and image is created (Hollands, 2008).

\subsection{Frameworks}

Smart city is defined in three ways- technology- oriented vision, approach oriented vision and service oriented vision.

- ICT oriented vision system which interconnects to promote optimum performance \& efficiency to create 'systems of systems'.

- Service oriented vision which further consists of dimensions of Smart Economy, Smart Governance, Smart Mobility, Smart Environment, Smart People and Smart Living for self-decisive, independent and aware citizens.

- Approach oriented vision which empowers the collective intelligence and in cocreating capabilities of the $4 \mathrm{P}$ model public, private, people and partnership.

\section{Understanding the Indian Context}

\subsection{Urbanisation in India}

Urbanization is one of the biggest challenges which both developed and developing countries across the world are facing. In 2015, the urban population in India was 410 million people (32\% of the total population) and was expected to reach 814 million (50\%) by 2050 . Three of India's metropolitan areas are among the most populous in the world: Delhi (25 million), Mumbai (21 million) and Kolkata (15 million) rank 2nd, sixth and 14th, respectively (WEF, 2016). This 'disordered urbanization' is indicative of the failure to adequately address congestion constraints that arise from the pressure of urban population on infrastructure, essential services, land, housing, and the environment (Velmurugan, S. et al., 2016).

\subsection{Emerging urban landscape of India}

According to World economic forum (2016), the landscape of India has undergone a dramatic change between 2004 -2014 where India witnessed an increase in urban

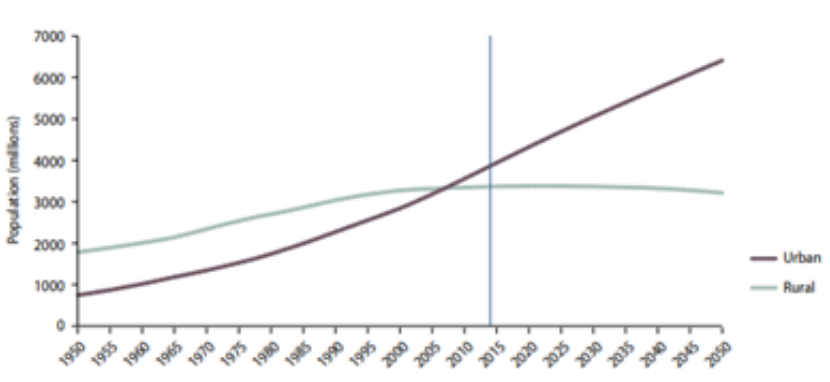
population from $14 \%$ to $27 \%$ while the rural population grew only $8 \%$.

This shortcoming is due to the weak local governments and the complex urban regime, which prevails in the cities.

Figure 3 Urban and rural population of the world. World urbanization prospects, 2014 


\subsection{Why Delhi is a special Case}

New Delhi, India's capital, is of particular interest not only because of the high level of air pollution and traffic congestion but also because of the exposure levels experienced by a population of 18.6 million. Delhi has astounded the World with its transformation, from feudal backgrounds to modernity, Delhi with its rich past is the perfect contrast between Occident and the Orient. It is a relevant example of a city that responds to the dualities of urban India while keeping its physical form legible. The government of India launched the scheme to create hundred smart cities across the country where the national capital Delhi was chosen to be the frontrunner to decongest national capital and facilitate modern abilities despite its limitations in the current scenario of economic \& environmental performances \& people's perceptions.

Spatial structure - According to Delhi development authority (2014), Delhi has grown as a borderless city where the urban agglomeration area has increased from an ordinary $43.2 \mathrm{sq}$. $\mathrm{Km}$ (1901) to 888.74 sq. Km (2001) while the density increased from 5501 (1901) persons per sq. Km to 14521 (2001) sq. Km.

Economic Profile - Delhi is India's second largest economy with per capita income of $€ 4125$ (2018) which is three times higher than the national average. The gross state domestic product (GSDP) has recorded a growth rate of $8.14 \%$ and presently is $€ 93.2$ billion.

Governance complexities - Delhi faces complex issues in an administration with the government running at three different levels- macro, state \& local body. The New Delhi municipal council is one of the five urban local bodies in the national capital territory (NCT) of Delhi, while the central government has most of the controlling power.

\subsection{Urban Transport Scenarios in Delhi}

Delhi seems to lack an institution that holds an overarching responsibility for managing and coordinating the entire transport sector. Delhi is in a situation where things need to move quickly for the present as well as precisely for the future for the safe travel with reduced level of pollution and congestion.

\section{Emerging patterns and characteristics Vehicle ownership-}

According to Delhi Statistical Handbook 2011, the vehicles in Delhi have grown at the rate of 7.41\% per annum between 2003-04 and 2010-11 where the number of private vehicles has increased substantially from 3.98 million to 6.52 million during that period where the growth rate of commercial vehicles $(9.42 \%)$ is higher than the growth rate of private vehicles (7.29\%).

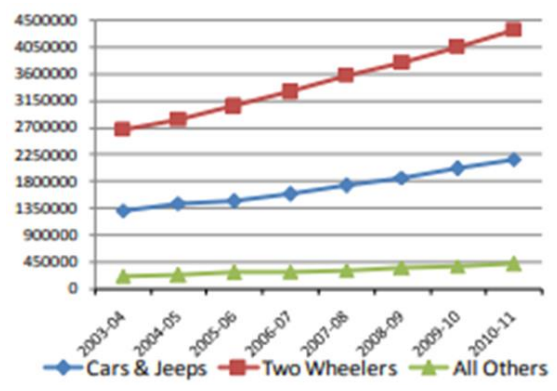

\begin{tabular}{|l|l|l|l|l|}
\hline S.N. & Category of Vehicle & \multicolumn{2}{|c|}{$\begin{array}{c}\text { No. of vehicles (in } \\
\text { million) }\end{array}$} & $\begin{array}{c}\text { Annual Compound } \\
\text { Growth Rate }\end{array}$ \\
\cline { 3 - 4 } & & $\mathbf{2 0 0 3 - 0 4}$ & $\mathbf{2 0 1 0 - 1 1}$ & \\
\hline 1. & Private Vehicles & 3.98 & 6.52 & $7.29 \%$ \\
\hline 2. & Commercial Vehicles & 0.22 & 0.42 & $9.42 \%$ \\
\hline \multicolumn{2}{|c|}{ Total } & 4.20 & 6.93 & $7.41 \%$ \\
\hline
\end{tabular}

Figure 2- Vehicular growth in Delhi, Census of India, 2011 
II. Vehicle density

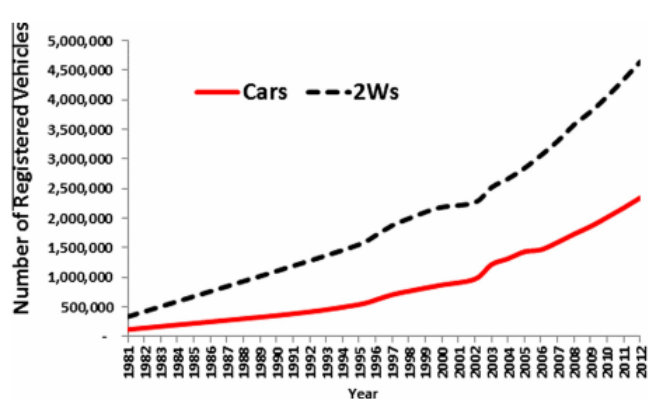

The vehicular population o Delhi has increased by more than nine times from 1971 to 1991 whereas the road length increased by only 206 times which has resulted in high vehicle density because of reduced vehicular speed causing more extended time travel, accidents and extra fuel consumption (Kumar et al., 2002).

Figure 3- Vehicle registration in Delhi, Census of India, 2011

III. Travel demand

\begin{tabular}{|c|c|c|c|c|c|c|c|}
\hline \multirow{2}{*}{$\begin{array}{l}\text { S1. } \\
\text { No }\end{array}$} & \multirow{3}{*}{$\begin{array}{c}\text { Mode of } \\
\text { Transportation } \\
\text { Facilities }\end{array}$} & \multicolumn{3}{|c|}{2001} & \multicolumn{3}{|c|}{2011} \\
\hline & & Rural & Urban & Total & Rural & Urban & Total \\
\hline & & 169528 & 2384621 & 2554149 & 79115 & 326142 & 3340538 \\
\hline & Bicycle & 48.70 & 36.80 & 37.60 & 44.20 & 30.30 & 30.60 \\
\hline 2 & $\begin{array}{l}\text { Scooter/Motor } \\
\text { CCcles M }\end{array}$ & 20.70 & 28.50 & 28.00 & 38.50 & 38.90 & 38.90 \\
\hline 3 & Car/Jeep/Van & 7.30 & 13.40 & 13.00 & 10.80 & 21.00 & 20.70 \\
\hline 4 & $\begin{array}{l}\text { None of the } \\
\text { Specififed Mode of } \\
\text { Transportation }\end{array}$ & 38.90 & 43.40 & 43.10 & 34.70 & 37.20 & 37.10 \\
\hline
\end{tabular}

The travel demand arose from 4 million trips per day (1994) to 20 million trips per day by 2011, in which the road based transport need to fulfil 12 million trips (403\% increase) while the daily trips were 22.5 million in 2011(Kumar et al., 2002).

Figure 4- Distribution of mode of transportation in Delhi, Census of India, 2011

\subsection{Transportation problems in Delhi}

\section{Road congestion}

The increases in population directly co-relates to the average travel distance and intensity. The average trip length for Delhi is around $22 \mathrm{~km}$ and this trend in trip length and frequency is only expected to increase with an increase in income levels, migration, participation of women and service-oriented economy but since more people travel over longer distances on a regular basis for employment and education purposes, it leads to road congestion (IIHS, 2015).

\section{Parking problems}

The acute shortage of parking spaces both on and off the street in Delhi increases the time spent in searching for a parking spot, which induces traffic congestion. $14 \%$ of road length in Delhi used on-street parking, and the public parking charges are fixed and low (€ 0.13 for 8 hours) (IIHS, 2015).

\section{Air pollution}

Delhi's air quality has become worse than before. According to the Environment Pollution Control Authority (EPCA) report for the decade 2002 to 2012 shows that the number of vehicles increased by 97 percent, contributing enormously to pollution and direct exposure to vehicular toxic fumes to nearly 55 percent of Delhi's 17 million people who live within 500 meters from any roadside (CSE, 2014).

\subsection{Barriers}

Based on the literature study and expert interviews, the barriers (Rana, NP et al., 2018) which hinders the smart mobility in Delhi. 


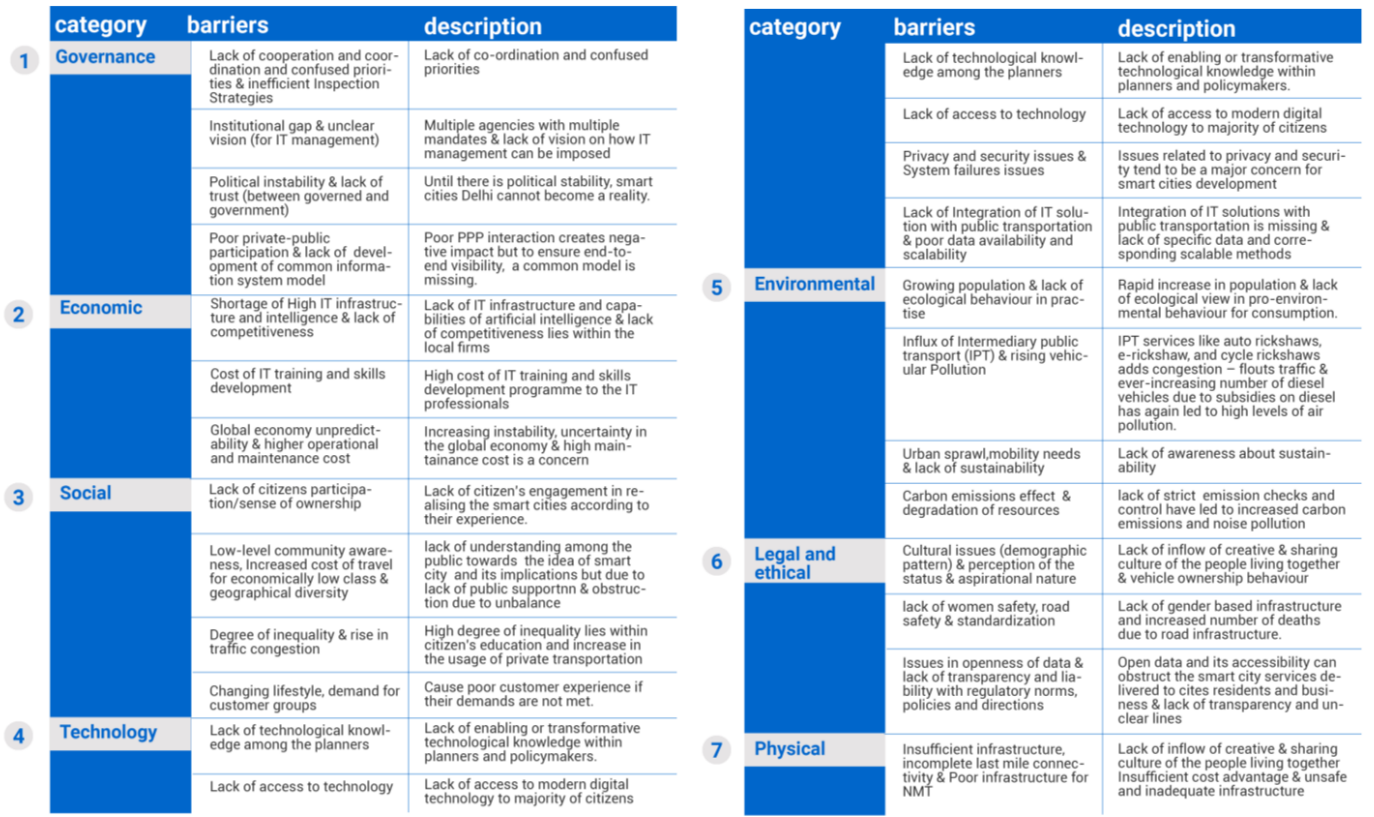

Table 1: Barriers in the India to adopt smart city principles quickly

\subsection{Megatrends influencing smart mobility}

Following key technologies can bring a range of new functionalities to reduce congestion, bring the social and economic changes for future of mobility 2040 for Delhi.

- $\quad$ Automated Vehicles

- $\quad$ Next generation connectivity using ICT

- Intelligent processing using Big Data and User applications

- Internet of things

- Innovative materials and Sensors in infrastructure

- User centred

- $\quad$ Pricing and payments

- $\quad$ Public and private innovation

\section{Analysis}

\subsection{Annual household disposable income}

\begin{tabular}{|c|l|l|l|l|l|}
\hline & $\mathbf{2 0 1 5}-\mathbf{2 0 2 5}$ & Category & Income & Characteristics & Categories \\
\hline 1 & $\mathbf{- 1 3 \%}$ & Deprived & $<\$ 1969$ & Poorest Group & $\begin{array}{l}\text { Engaging in un-skilled or low- } \\
\text { skilled activities }\end{array}$ \\
\hline 2 & $\mathbf{- 7 \%}$ & Aspirers & $\$ 1969-\$ 4376$ & Struggle to live comfortably & $\begin{array}{l}\text { Small-time shopkeepers/ service } \\
\text { workers }\end{array}$ \\
\hline 3 & $\mathbf{+ 1 3 \%}$ & Seekers & $\$ 4376-\$ 10,941$ & $\begin{array}{l}\text { Varied in employment, attitude, } \\
\text { age and other factors }\end{array}$ & $\begin{array}{l}- \text { Mid-level government official } \\
- \text { Traditional white collar jobs }\end{array}$ \\
\hline 4 & $+\mathbf{+ 8 \%}$ & Strivers & $\begin{array}{l}\$ 10,941- \\
\$ 21,882\end{array}$ & $\begin{array}{l}\text { Very sucessful } \\
\text { Financially stable }\end{array}$ & $\begin{array}{l}\text { Businesspeople/ traders } \\
\text { Established professional/ }\end{array}$ \\
\hline 5 & $\mathbf{+ 1 \%}$ & $\begin{array}{l}\text { Global } \\
\text { Indians }\end{array}$ & $>\$ 21,882$ & $\begin{array}{l}\text { New breed of upward } \\
\text { mobile-mid-level executives }\end{array}$ & $\begin{array}{l}\text { Senior corporate executives/ } \\
\text { large business owners }\end{array}$ \\
\hline
\end{tabular}

Table 1: Comparable from Deloitte, McKinsey \& Company, Rise -Indian consumer market 2007 


\subsection{Existing Personas}

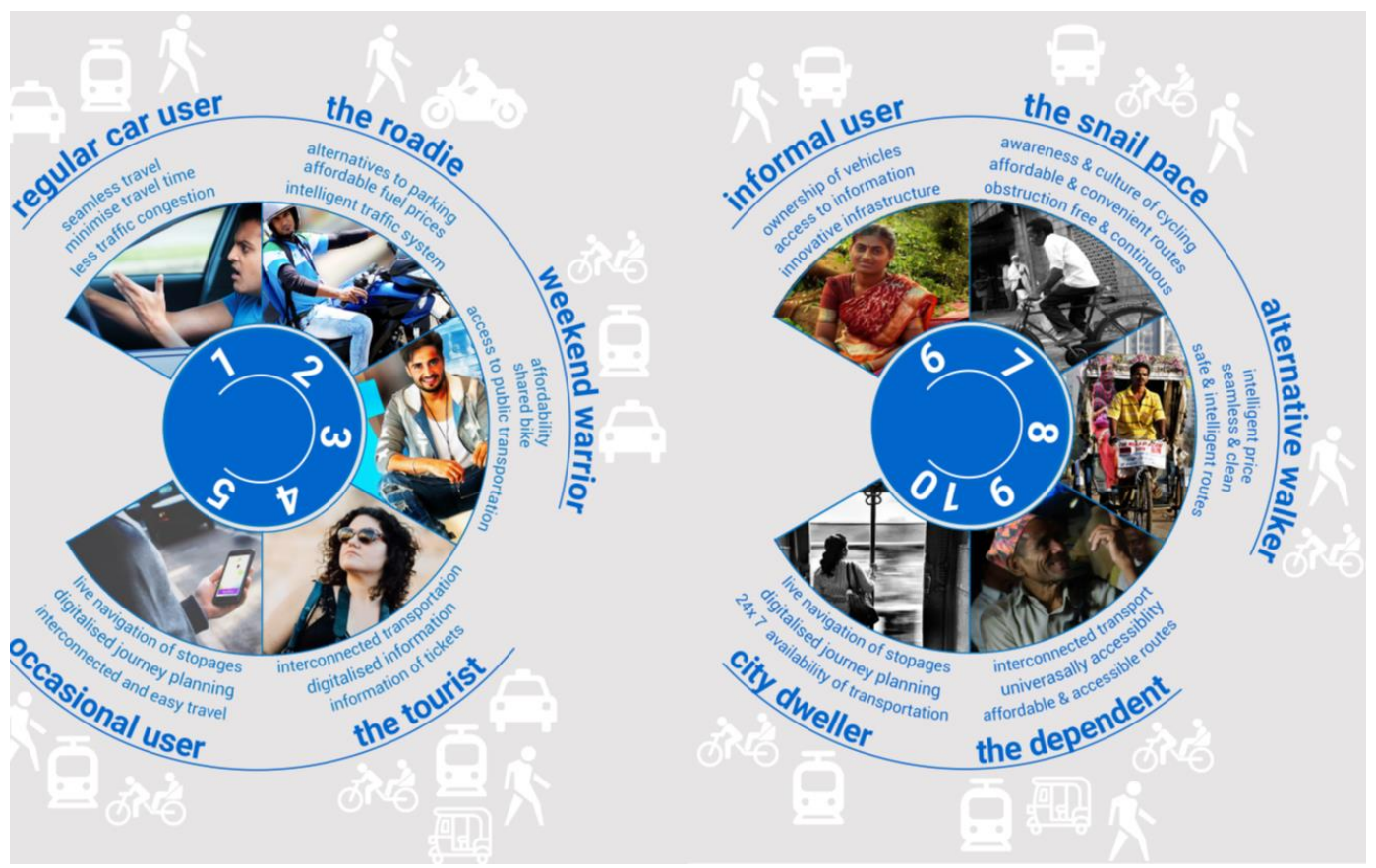

Figure 5- Analysis of 10 different existing user journey on their painpoints \& future goals

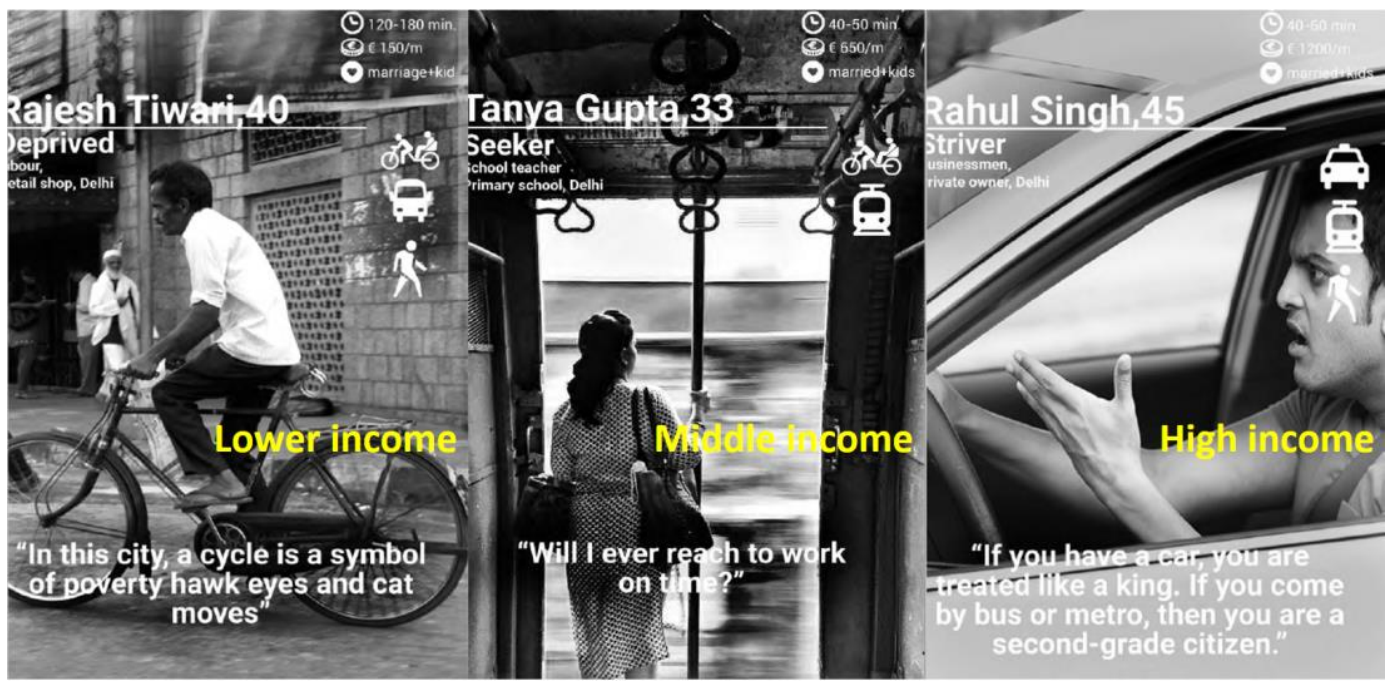

Figure 6- Three classifications of existing users based on income scale 


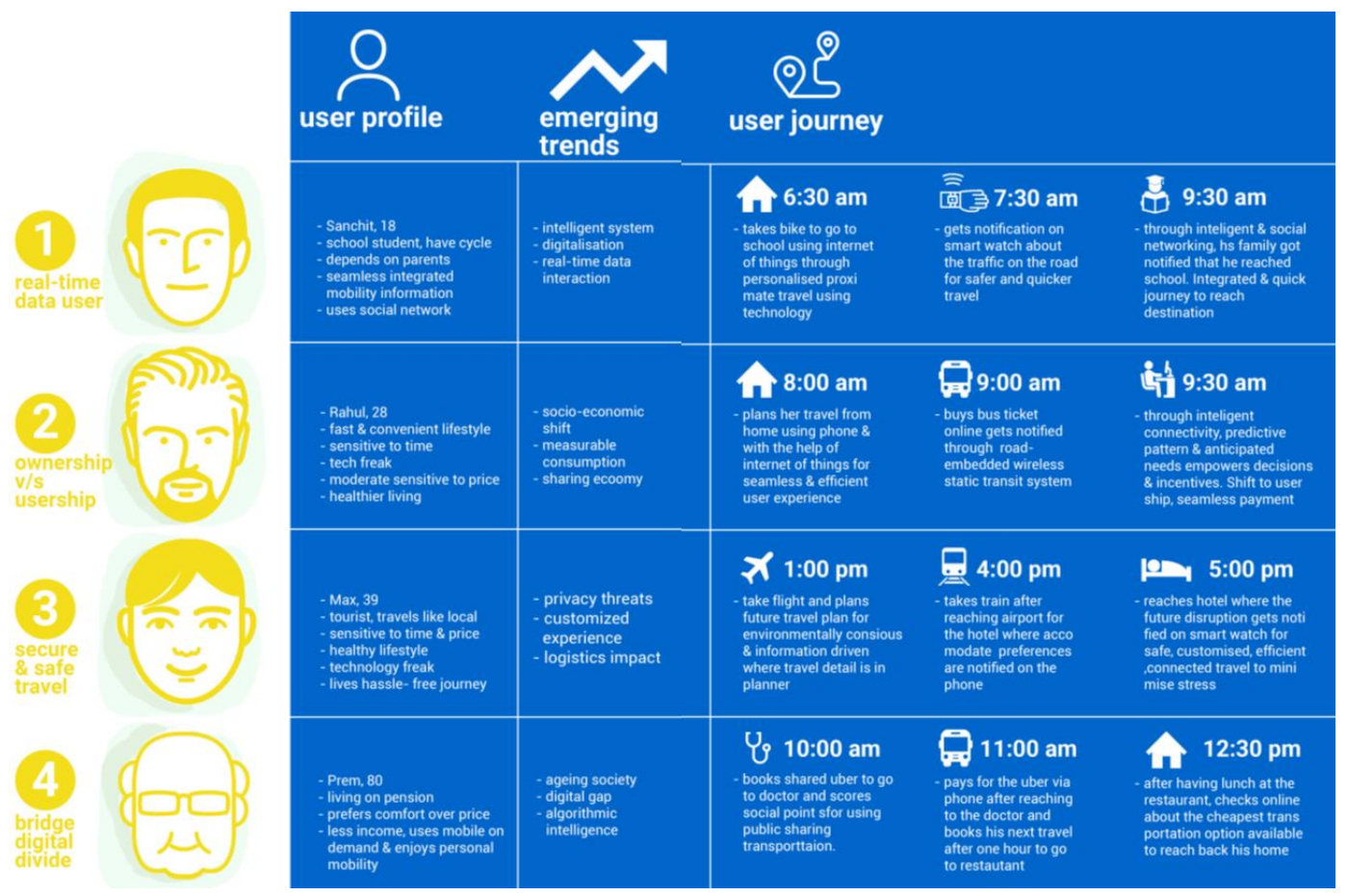

Figure 7- Future User journey based on the emerging trends

\section{Recommendations}

\section{Future Scenario: Live Glocal}

Though it's difficult to make detailed predictions for the future of mobility, but it's not so hard when current trends are grouped with features of being enormously networked, integrated, dynamic pricing, user-centered with the development of both public and private stakeholders since we have to recognize that no single solution would save transportation from in this rapidly urbanizing and complex world. This scenario is notable by the lower per capita travel and the high use of digital substitution of ICT, user applications and internet of things for travel. Changes in the environmental and social behaviour for travel demand is visible with focus on uplifting the informal transportation, increased employment, and last mile connectivity. In this scenario, automation is not widely adopted by the public. The future of mobility is likely to be fundamentally based on broadly connected vehicles, or "the internet of cars", prices as per demand and supply; and transportation decision making through social networking but would be highly dependent on the interplay of various stakeholders from public (government, institutions) and private sector (manufacturers, entrepreneurs) as reflected in the scenario below. What will be the possible steps to reach there?

\section{Economic Trends}

11,000 new e-rickshaws are expected to ride on the streets of Delhi every month by 2021 where annual sales are supposed to increase by 9 percent making it $€ 1.32$ billion markets (Economic times, 2018). However, with increased demographics by 2040 , the demand for informal transportation using ICT would be increased and thus encouraging an affordable ecosystem of technology. 


\section{Technology}

The E- mobility is shaping the informal transportation for Delhi with the increased use of Erickshaws, thellas, etc. which play a significant role for enhancing the last mile connectivity and thus improving the air quality of Delhi. Technology-driven trends like electrification, shared mobility and connectivity would be a disruption in this scenario. However, due to several loopholes, initiatives have to be taken by the government to improve the informal transportation sector (Down to earth, 2018).

\section{Travel implications}

Though the travel will be much more expensive by 2040 in this scenario for informal sector due increased road pricing, digitalization, higher travel demands but a change in the acceptance and commuter's behaviour would be visible due to improved technological advancement in transportation industry with rising in ride-sharing apps, travel information applications with increased user's experience and seamless travel.

\subsection{Step: 1- Dynamic payment}

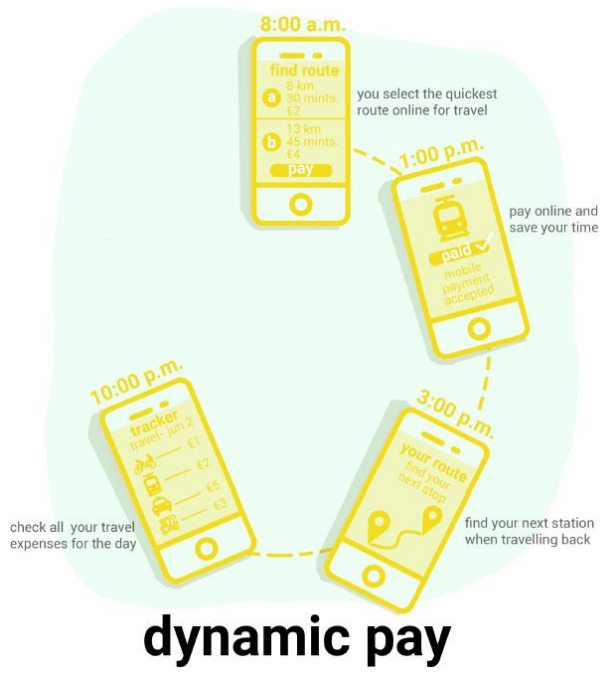

Figure 8- Dynamic payment
Transportation industry is moving towards the notion where services will no more be priced statically due to widespread of mobile technology, location-based services, and predictive forecasting will allow to pay actual costs of the services used where the price (supply) would be based on the demand which will allow the users to make better decisions about their travel as per their needs. This will allow the commuter to choose their between the lowest cost and quickest routes with the help of real-time reporting traffic conditions for their final destination.

\section{Concern}

- Who would be in charge to determine the difference between the benefits, loses/ negative impact of the system where the providers have set the prices as per the demand, and other considerations of the services on their own? What will be the overall impact for setting the prices as per demand?

- $\quad$ Should there be a potentially competitive market for the mobility as a service or should the pricing be dependent on the community or economic background of the social group for the commuter?

How to get there?

- $\quad$ By exploring new payment business models

- $\quad$ Promoting digital payments

- $\quad$ Predicting about the needs and desires of the future transportation market 


\subsection{Step: 2-Social Move}

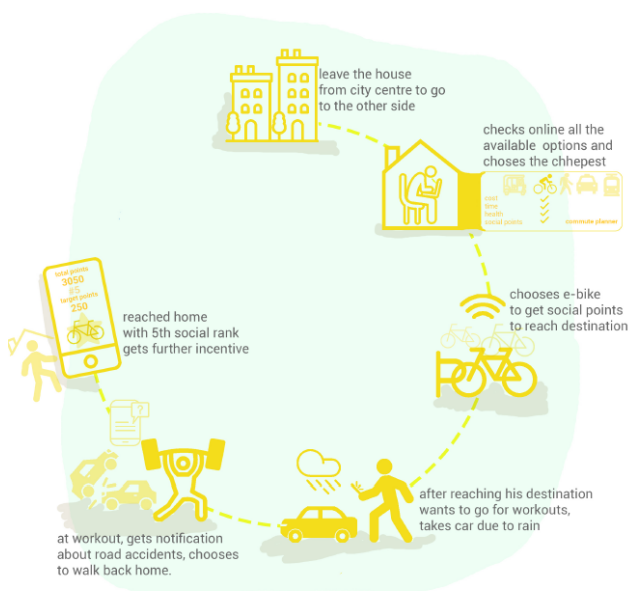

social move

Existing transportation systems lacks in connecting all the various transportation system directly but with the rise of networked cars, awareness, social network, the future of transportation will be based on socially informed decisions of the communities, government, traffic controllers, real-time travel conditions and community values from people who have already used it for experiential travel. Creating gamified experience which encourages fitness, saves money and provide business benefits and loyalty with the users to the services.

Figure 9- Social move

\section{Concern:}

- $\quad$ Difficulties in getting a holistic view as information would be scattered and based on the decisions of various people.

- $\quad$ Might create differences with the people who will not be able to attend the network or lack the ability to influence or engage to become second-class inhabitants. Will these people be able to take the benefit of such social network system?

How to get there?

- $\quad$ Analysing the changing behaviour and designing user-centric solutions

- $\quad$ Providing social points as incentives and creating a gaming experience for users which allows to compare their social points for changed travel behaviour

\section{Conclusions}

Cities are dynamic. Cities are its people. It changes and adapts over time in response to economic, political and environmental shifts where the infrastructure is not the driver but an enabler, a side effect or a by-product of people and culture.

However, a city cannot be 'smart' and inefficient at the same time and therefore, high activity is far more important than the big idea for enabling the citizens to make informed decisions. For smart cities, context is more important than the product but can this smart city be simply rebooted through the integration of digital technologies? Is this 'smart urbanism' branded, exaggerated in offering 'new possibilities' for the future transformation of cities or it is a brain-dead idea of 'business as usual' value propositions for tweaking the existing scenario through technology and influence from western countries? To access the technology advancements and its potential impacts for the society, monitoring of the future technologies is substantial because technology is not the 'shortcut for development' but it 'can be an accelerator.' 
As transportation is the backbone of economic, cultural, social and industrial development, the transformation of existing urban areas to mitigate the existing challenges in a traditional society like India was a concern despite its rising economy and therefore understanding the existing spatial dynamics, hopes and fears about the technology, core needs and expectations of the transportation users was accomplished by analyzing the existing user groups to propose the experiential design for users using technology and services. India gives the appearance of just waking up to the urban realities and the inevitable transformation awaiting its cities. India's attempts to urbanization have been at a snail's pace, and the smart cities mission seem to be a knee-jerk reaction to the sudden realization of not wanting to be left behind (Chandrasekar, S. et al., 2016).

Delhi is a paradox where despite the increasing challenges it provides opportunities to shape the future of mobility. No single solution can be recognised for the rapidly urbanising and complex mobility situation of Delhi as the innovations are rarely linked and optimized to provide convenient, practical, affordable and sustainable door-to-door trips for the users. Connectivity is the key, but accessibility is the goal for the future of mobility as transportation is a system, or rather a 'system of systems' which connects modes, services, technologies, and designs according to the purpose and needs of the people.

The future of mobility lies in the seamless transportation experience can be accomplished by physically connecting the transportation modes and services for the community, bringing together the telecommunications framework which offers real-time information of availability (departures and arrivals), access to affordable or convenient ride and quick payments. In some places, it is almost therein Delhi but not evenly distributed. It can be achieved through connecting Spatial (physical linking the transportation modes), component (enhancing the accessibility capabilities with improved infrastructure), technological (technologies to support multi-modal transportation for seamless experience), institutional (transforming collectively on local and regional level with the help of planners, city officials, innovators, etc.) and economic (developing new business models, creating jobs and increasing competitive market) optimisation of Delhi

With the shifting mobility needs and customer expectations, the future of mobility has to evolve and adapt to provide intelligent connectivity for enabling effective, seamless and endto-end journey experience. Analysing the existing users' needs and desired helped to explore the future user journey under the themes of user-ship vs ownership, big data eco-system, Bridging digital divide and safe travels to engage the range of issues: enable better choices with smarter decisions; predictive dependable and productive mobility; cybersecurity; public safety; and mobility opportunities for everyone where distinct stakeholders like users, municipalities and owners/operators play a critical role for a safer, healthier and better user journey experience.

Live Glocal scenario describes a future of moderate growth in which incomes do not rise quickly in future informal transportation but high usage of technology for travel steered the economy towards a more sustainable path for growth and enacted constraints on vehicle ownership and driving to try to reduce their negative impacts which results in a future of strong travel demand across all modes of transportation and improved last mile connectivity. Dynamic payment and social transport to widen the recognition of 'information everywhere' to disrupt the transportation status quo and bring new ways of using existing infrastructure more efficiently with high speed and offers the chance to 
rethink the existing challenges for mobility of Delhi and prepares the eco-system with set of features. Through reshaping how urbanites in Delhi would get around by introducing mobility as a service and collective intelligence of the citizens might help in making better decisions but cities will need to explore the digital mobility platforms to accelerate the realization of the integrated transportation system.

Successful urban planning process can be creative, flexible and democratic because reality comes into being through interaction. However, the more significant question lies in what is next for the smart city in India? Smart cities will not be a recipe for social segregation only if inclusivity is considered along with the booming of technological development has encouraged multiple vision for urban futures of India and analyzed the 'surface' of many cities but there exist troubles with determinism and attitude of government towards the socio-political changes and consequent ways of owning and managing the initiatives as this give rise to the 'classic dilemma' for urban space and governance which affects the lifestyles of the emergence of the information society. Does this 'virtually enhanced city' in which we would live and communicate need more control or does it need more open participation? How can these two aspects be integrated? Should the smart city's ethos be oriented towards service provision with better city management or should it focus on enhancing the social and political linkages for public discourses? Does the policies and technological initiatives aim at the 'end-users,' or it is aimed by the 'actors and owners' of the city?

Technology will only enhance the future of smart mobility if the technology works around the 'existing behaviors'. Technology is interesting and is the future only when it interacts according to the human understanding and therefore, understanding the value exchange is important which can be implemented by encouraging gamified experiences that is helpful to get the loyalty of the services using the long-term relationship and big data. Though the future lies in the hidden connections as it is not difficult to change the city but to change their mindsets. Therefore, evolving a mobility landscape after understanding the patterns of consumer behavior and analyzing how to build the services around the existing infrastructure with 'on-demand' and personalized mobility services also known as 'mobility as a service (MaaS)' will unlock the potential for innovation for the city to function on a larger scale.

Things which are hardly mentioned in the 'smart cities propaganda' is the 'other side of the city' and therefore the 'branding' of smart cities have to do by keeping and creating the spirit and emotions of India. Who wants smart cities and who does not want to be seen as being smart? Does the discourse of smart in India explore the global explorations with the value of smart cities or with the needs and realities or urban India? In order to understand the algorithmic urbanism of smart Indian cities, the examining of the politics of a country is essential. What is next to cities or what could be next for cities if we dare to reimagine ourselves? What is next for the future of mobility? Are we there yet? Will Delhi be a city of things or a city for people?

\section{References}

Alice Charles: India wants to create 100 'smart cities' - how can it get there? World economic forum, 2016

Baindur, Deepak: Urban Transport in India: Challenges and Recommendations. India, 2015 
Delhi Development Authority (2014) Ministry of urban Development, GOI Draft Master Plan for Delhi 2021

Hollands, R: Will the real smart city please stand up? Leuven, 2008.

Komninos, N.:"Intelligent Cities and Globalisation of Innovation Networks", London and NewYork, Routledge, 2008.

Kumar, Sujeet: Indians promised benefits of 100 smart cities, but the poor are sidelined again. India, 2018

Mitchell, W. J.: Intelligent cities. Knowledge Society - Universitat Oberta de Catalunya, 2008

Rana, Nripendra P.; Luthra, Sunil; Mangla, Sachin Kumar; Islam, Rubina; Roderick, Sian; Dwivedi, Yogesh K. (2018): Barriers to the Development of Smart Cities in Indian Context. In Inf Syst Front 37 (3), p. 99. DOI: 10.1007/s10796-018-9873-4.

R.G. Hollands: "Will the Real Smart City Please Stand Up?" City: Analysis of Urban Trends, Culture, Theory, Policy, Action 12: 3 (2008) 303-320.

Velmurugan, S., Ravinder, K., Madhu, E., Nataraju, J., Sekhar, C.R., Kumar, P.V.P., Kumar, R., Umat, S.K., 2012. Evaluating Bus Rapid Transit (BRT) Corridor Performance from Ambedkar Nagar to Moolchand, Delhi (No. Final Report). Central Road Research Institute, Delhi.

8am-8pm is new 'Delhi rush hour': CSE study - Times of India. India, 2017 